\title{
Additive Manufacturing in Dentistry: Current Technologies, Clinical Applications, and Limitations
}

\author{
Methani, Mohammed M ; Cesar, Paulo Francisco ; de Paula Miranda, Ranulfo Benedito ; Morimoto, Susana ; \\ Özcan, Mutlu ; Revilla-León, Marta
}

\begin{abstract}
Purpose of Review This review aimed to illustrate the utility of additive manufacturing technologies for the fabrication of polymer, metal, and ceramic components within the confines of their current and potential clinical applications in dentistry. Recent Findings The literature reviewed on five additive manufacturing technologies, namely, vat-polymerization, material jetting, material extrusion, powder-based fusion, and binder jetting, have been investigated in relevance to their dental applications. These technologies have the following existing or potential clinical applications: diagnostic and definitive casts, custom trays, positioning guides for custom abutments, tooth preparation guides, interim dental restorations, all-ceramic crowns, metal crowns and copings, silicone indices, occlusal devices, complete dentures, wax patterns for intra- and extra-coronal restorations, surgical guides, removable partial dentures, and tooth- or implant-supported frameworks. Summary Vatpolymerization, material jetting, and powder-based fusion technologies have existing clinical applications utilizing mainly polymers and metals. Additive manufacturing technologies need further development to be used with ceramic materials for dental applications.
\end{abstract}

DOI: https://doi.org/10.1007/s40496-020-00288-w

Posted at the Zurich Open Repository and Archive, University of Zurich

ZORA URL: https://doi.org/10.5167/uzh-198913

Journal Article

Accepted Version

Originally published at:

Methani, Mohammed M; Cesar, Paulo Francisco; de Paula Miranda, Ranulfo Benedito; Morimoto, Susana; Özcan, Mutlu; Revilla-León, Marta (2020). Additive Manufacturing in Dentistry: Current Technologies, Clinical Applications, and Limitations. Current Oral Health Reports, 7(4):327-334.

DOI: https://doi.org/10.1007/s40496-020-00288-w 


\section{Additive Manufacturing in Dentistry: Current Technologies, Clinical Applications and Limitations}

Mohammed M. Methani ${ }^{1} \bullet$ Paulo Francisco Cesar $^{2} \bullet$ Ranulfo Benedito de Paula Miranda $^{3} \bullet$ Susana Morimoto ${ }^{3} \bullet$ Mutlu Özcan ${ }^{4} \bullet$ Marta Revilla-León ${ }^{5}$

${ }^{1}$ University of Minnesota, School of Dentistry, Orofacial Pain residence, Minneapolis, MN, USA

${ }^{2}$ University of São Paulo, Department of Biomaterials and Oral Biology, School of Dentistry, São Paulo, Brazil

${ }^{3}$ Ibirapuera University, School of Dentistry, São Paulo, Brazil

${ }^{4}$ University of Zurich, Center of Dental Medicine, Division of Dental Biomaterials, Clinic for Reconstructive Dentistry, Zurich, Switzerland

${ }^{5}$ Texas A\&M University, College of Dentistry, Dallas, TX, USA; Affiliate Faculty Graduate Prosthodontics, University of Washington, School of Dentistry, Seattle, WA, USA and researcher at Revilla Research Center, Madrid, Spain

M. Revilla León*

Texas A\&M University, College of Dentistry, 3302 Gaston Avenue, Room 713 Dallas, TX 75246, USA e-mail: revillaleon@tamu.edu 


\section{Abstract}

Purpose of review: This review aimed to illustrate the utility of additive manufacturing technologies for the fabrication of polymer, metal and ceramic components within the confines of their current and potential clinical applications in dentistry.

Recent findings: The literature reviewed on five additive manufacturing technologies namely, vatpolymerization, material jetting, material extrusion, powder-based fusion and binder jetting have been investigated in relevance to their dental applications. These technologies have the following existing or potential clinical applications: diagnostic and definitive casts, custom trays, positioning guides for custom abutments, tooth preparation guides, interim dental restorations, all-ceramic crowns, metal crowns and copings, silicone indices, occlusal devices, complete dentures, wax patterns for intra and extra-coronal restorations, surgical guides, removable partial dentures and tooth- or implant-supported frameworks.

Summary: Vat-Polymerization, material jetting and powder-based fusion technologies have existing clinical applications utilizing mainly polymers and metals. Additive manufacturing technologies need further development to be used with ceramic materials for dental applications.

Keywords 3D printing • Additive Manufacturing • Prosthodontics 


\section{Introduction}

Introduction of digital technologies have changed the workflow and thereby position of dental medicine, not only from clinician's but also from patient's perspective. With the rising demands for expedited dental treatments, practitioners and researchers are relentlessly speculating to automate and standardize the processing of dental materials. This paradigm shift has frequently been epitomized as "digital workflow" in dentistry that is based on three quintessential elements, namely data acquisition, data processing, and data manufacturing [1].

"Data acquisition" refers to the procurement of a digital geometry of the intraoral tissues using an intraoral scanner (IOS) and/or desktop digitizer. The digital image is used as a substrate to consummate the virtual design of the restoration, which is known as "data processing". This virtual design is labelled as the standard transformation language (STL) file. "Data manufacturing" on the other hand, is the final step in the sequence of digital workflow, which involves transfiguration of the virtual STL file to its physical form [2].

Data manufacturing can be accomplished through additive or subtractive technologies. Subtractive manufacturing (SM) refers to computer-controlled milling of a solid block of a given material for the fabrication of the desired restoration [3] while additive manufacturing (AM) has been defined by the American Society of Testing and Materials (ASTM) as "the process of joining materials to make objects from 3D model data, usually layer upon layer, as opposed to subtractive manufacturing methodologies" [4]. Even though SM has been routinely used for the better part of at least the past two decades for the fabrication of dental restorations, innate drawbacks of this technology include raw material waste, untenable wear of the milling tools, limited geometric reproducibility and introduction of microcracks in the restoration. AM however, is a relatively novel technology that has 
begun to sideline SM as the final step in digital workflow by virtue of its versatility and customization possibility in manufacturing complex geometries. The International Organization for Standardization (ISO-TC 261/ISO 17296-2:2015) has classified AM into seven categories: vat-polymerization (VP), material jetting (MJ), material extrusion (ME), binder jetting (BJ), powder base fusion (PBF), sheet lamination (SL), and direct energy deposition (DEP) [5]. In almost all disciplines of dentistry, accuracy and trueness parameters are considered of importance for the precision of the final product.

The accuracy of a 3D printer is defined by two parameters, one being trueness and the other precision. Trueness is a measure of the dimensional disparity between the actual object and its AM transcription, while precision refers to the dimensional reproducibility or repeatability associated with multiple iterations of an AM transcript. The limit to the smallest detail which each technology can reproduce from the original STL file is called "resolution". For a 3D printer, each axis $(x, y, a n d z)$ is characterized by its own resolution in dots per square inch (dpi), with the $z$ axis corresponding to layer thickness [6].

The objective of this review was to evaluate the current AM technologies and possible clinical applications in context of the manipulation of major classes of biomaterials used in dentistry with a particular focus on metals, polymers and ceramics [7].

\section{VAT-POLYMERIZATION}

Four different vat-polymerization (VP) technologies can be differentiated based on the light source employed for polymerization: stereolithography (SLA), digital light processing (DLP), liquid crystal display based (LCD), also called daylight polymer printing (DPP), and continuous liquid interface production (CLIP). 
SLA procedure uses a laser or an ultraviolet (UV) light to fabricate the desired object layer by layer. The build platform descends sequentially in a vat filled with photosensitive resin, followed by exposure to the UV light in a pattern dictated by the cross-sectional geometry of each layer of the object. In order to bolster the object against the wiping action of the build platform and gravity, support structures are used that supplement the STL file prior to printing. The manufactured part is then subjected to post processing procedures, which involves removal of excess resin and support structures, followed by polymerization in an UV chamber.

Digital light processing (DLP) is based on vat-polymerization technology but differs from the SLA on the light source employed. DLP uses a digital micro-mirror device (DMD) to reflect the light and polymerize each layer [8] whereas LCD or DPP technology uses daylight projected onto liquid crystal displays (LCD) in lieu of UV lasers or projectors to polymerize the resin, which renders it inexpensive relative to other technologies. Lastly, the CLIP technology uses a DMD to polymerize the photosensitive resin through an oxygen permeable window made of fluoropolymer that creates an area called "dead zone", where polymerization is inhibited between the window and the polymerized part. CLIP builds the 3D object in a continuous rather than a stepwise fashion, hence expediting the production process [9].

In general, the resolution of a vat-polymerized printed object is characterized by the properties of photosensitive resin and processing parameters including light energy, wavelength, speed of the printer, build platform positioning, slicer software, printing parameters, support structures, printing angulation, resin color, geometry of the object, and post-processing procedures [10-12]. 


\section{Polymer-based dental applications of vat-polymerization technologies}

VP technologies can be used to manufacture a wide array of polymer-based devices in dentistry namely diagnostic casts, custom trays, positioning guides for custom abutments, tooth preparation guides, interim dental restorations, silicone indices, occlusal devices, complete dentures, patterns to cast or press dental restorations, and surgical guides.

One of the simplest applications of VP technology procedures was the production of diagnostic casts [8]. The accuracy of the casts obtained using VP procedures have been investigated in the dental literature reporting VP as clinically acceptable method to obtain diagnostic casts [13]. In an in-vitro study, Patzelt et al [14] compared the accuracy of the milled and AM diagnostic casts obtained from the digital scans performed with a laboratory scanner and three different IOSs. According to the results, SLA casts showed higher accuracy than their milled counterparts but the accuracy was still questionable at best for prosthodontic applications. Hazeveld et al [15] compared the accuracy of the diagnostic casts fabricated using three AM technologies (DLP, MJ, and PBF) where the results validated DLP as a clinically acceptable method for the fabrication of orthodontic casts.

VP technologies can also be used to manufacture definitive casts for tooth- or implant-supported prostheses. However, the dental literature pertaining to the accuracy of those casts is insufficient. The accuracy of definitive casts fabricated using this technology can be determined by evaluating spatial distortions of fixed reference points. Revilla-Leon et al [16] evaluated the dimensional distortion in implant replica positions within SLA, DLP, MJ and conventionally processed stone casts using a coordinate measuring machine (CMM). According to this study, DLP did not perform significantly better compared to conventional dental stone for cast duplication.

VP technology also allows for the fabrication of custom trays. Trays are crafted virtually on digital models using dental or open source computer aided design (CAD) software and subsequently 
constructed using a VP 3D printer. Digital manipulation of a custom tray provides several advantages such as control of the extensions of the tray, uniform thickness of the impression material, and minimization of the manual procedures. In some studies, VP technologies were utilized to fabricate custom trays impressions making procedures in implantology $[17,18]$.

Limited number of studies have investigated the biocompatibility, chemical composition, mechanical properties, and clinical behaviour of VP technologies for the fabrication of provisional restorations $[19,24]$. Tahayeri at al [25] reported that SLA AM provisional restorations showed comparable mechanical properties to their conventionally processed equivalents, which were considered adequate for intraoral use. Furthermore, Ahn et al [26] found significantly higher wear resistance for SLA and DLP provisional restorations in contrast to the conventionally processed resin. In another investigation by Cho et al [27], similar trends were observed in that fracture load and flexural strength of SLA and DLP processed interim restorations were comparable to those of milled and conventionally processed ones. Alharbi et al [28] evaluated the effect of the build-up orientation on the mechanical properties of cylinder-shaped hybrid composite resin printed specimens where vertically printed specimens with the layers oriented perpendicular to the load direction showed significantly higher compressive strength than horizontally printed specimens with the layers oriented parallel to load direction.

VP silicone indices have been utilized to run interference for diagnostic purposes in trial restorations, direct composite restorations, and interim restorations [29, 30]. Unlike conventionally processed indices, SLA indices mitigate chairside time by eliminating the need for manual diagnostic waxing and allowing for a precise intraoral translation of the digitally configured build-up [31]. Furthermore, VP processing of silicone indices is more cost efficient than the conventional procedures [32]. 
Also, several studies investigated VP technologies for the fabrication of occlusal devices [33-36]. Digital design and AM technologies optimize the fabrication of occlusal devices by circumventing manual labour associated with the process. [37]. A number of studies have reported that AM occlusal guard materials demonstrate comparable properties compared to their conventionally processed counterparts [34-36]; however, according to a study by Lutz et al [38], DLP printed occlusal devices demonstrate lower wear and fracture resistance than milled and conventionally processed devices. Contrarily, the results of an investigation by Prpic et al [39] and co-workers indicated that mechanical properties of an occlusal device were a function of material as opposed to the technology used. Further preclinical and clinical studies are recommended to evaluate the behavior of those AM occlusal devices.

VP procedures have also been used as tool for fabricating removable and complete dentures [4042] which involves individual printing and subsequent assemblage of denture base and teeth [43, 44]. The denture teeth produced using VP have demonstrated adequate fracture resistance to be used as complete denture components [45]. Moreover, SLA demonstrated a higher overall manufacturing accuracy than injection molded denture bases [46]. However, the surface finish reproduced via injection molding supersedes milling or printing, which coupled along with a dearth of clinical trials raising qualms about this proof of concept [47]. Further studies are recommended to evaluate the mechanical properties and long-term behaviour of the AM complete dentures.

The VP technology has additionally been investigated to produce wax patterns to obtain cast metal frameworks, tooth-supported prostheses, frameworks for removable partial denture (RPD) and pressed ceramic restorations [48-50]. AM is better suited than SM for the fabrication of complex nonuniform geometries, which are highly typical of RPD frameworks. Digital RPD frameworks are designed in a CAD software using 3D model data derived from an intraoral or laboratory scan of 
stone cast. Thereafter, the framework is printed as wax or plastic sacrificial pattern, which is then invested and casted in metal. In this regard, Williams et al [50] virtually designed an RPD framework on an electronically surveyed cast and utilized SLA for printing the sacrificial RPD framework in plastic.

A CAD software can also be used for digital waxing of patterns to fabricate casted and pressed dental restorations. The patterns are printed in wax, invested, and cast in metal or pressed in lithium disilicate ceramic. Studies have investigated the accuracy of final restorations derived from AM patterns $[48,49]$. Accuracy of the AM pattern were analyzed by evaluating the gap between processed final restoration and prepared tooth or model. Fathi et al [47] evaluated the marginal and internal discrepancies in pressed lithium disilicate crowns fabricated using handcrafted, milled and printed wax patterns. Accordingly, crowns fabricated using AM wax patterns demonstrated a clinically acceptable and superior fit than the ones fabricated using milled or handmade wax patterns [48]. These results are coherent with the outcomes of studies conducted by Mai et al and Kim et al $[51,52]$.

In the field of surgery, VP has been used for automatized production of surgical guides [53-57]. Digital casts and Cone-Beam Computerized Tomography (CBCT) data have proven to be reliable substrates for virtual fabrication and subsequent AM of surgical guides. Giacomo et al [53] used SLA printing for fabricating surgical guides, speculatively suggesting it as a useful tool for manufacturing guides and placing implants, contingent upon further clinical studies. Since then, however, several studies have achieved promising results within this domain. Sarment et al [55] reported improved implant placement with SLA AM guides designed using CBCT data. Additionally, Özan et al [56] analyzed the angular deviations in implant placement with tooth and mucosa supported SLA guides. According to this study, SLA guides obtained from CBCT data were considered to facilitate reliable 
implant placement using tooth supported guides. On the other hand, controversial results from the investigation of Reyes et al [54] reported better fit for conventionally processed surgical guides and among the SLA guides, the ones fabricated using optical scan as a substrate apparently demonstrated a better fit than CBCT configured guides.

\section{Ceramic-based dental applications using vat-polymerization technologies}

VP procedures for processing dental ceramics involves two additional steps where the first step involves thermal treatment for the removal of organic binders, and the second step is the high temperature sintering for densification of the ceramic. Dehurtevent et al [58] studied the feasibility of alumina slurries with $75 \%$ and $80 \%$ dry matter contents for SLA and demonstrated the fabrication of a maxillary premolar ceramic crown using alumina slurry with $80 \%$ dry matter content and large sized $(1.56 \pm 0.04 \mu \mathrm{m})$ particles. While in one study SLA manufactured ceramics exhibited higher fracture toughness than their dry pressed analogues [59], Zandinejad et al [60] found no significant differences in fracture resistance of milled and SLA zircona crowns. In terms of marginal and internal

fit however, Revilla-Leon et al [50] reported clinically acceptable values for SLA manufactured ceramic crowns.

In addition to ceramic crowns, SLA has been used to print zirconia implants with great dimensional accuracy [56]. Implant specimens manufactured at a 0-degrees angulation demonstrated significantly higher characteristic strength than the ones produced at a 45-degrees or 90-degrees angulation. However, microstructural analysis of the specimens revealed substantial porosities and cracks, which entails the pursuit of concrete evidence before the technology can make a transition into clinical practice [61]. 


\section{MATERIAL JETTING}

Material jetting (MJ) works similarly to ink jet printing but in contrast to single layer printing, the building tray descends sequentially with the printing and polymerization of each successive layer of the liquid photopolymer, eventually generating the 3D object. Material droplets are selectively deposited by different nozzles moving in the $x-y$ axis onto the building platform that traverses in $z-$ axis. The main advantages of this technique are high precision, low material waste and ability to print multiple materials in different color|IIIIIs since each nozzle may contain a different resin [6264].

\section{Dental applications using MJ technologies}

There is significant overlap in the clinical applications of MJ and SLA with respect to the fabrication of polymer-based appliances and prostheses. Even though MJ can print objects in multiple colors or materials, its application is limited to resins that are dispensable as inks. In fact, VP technologies are more frequently used than MJ technologies. Similar to VP, MJ can be used for printing diagnostic casts and using digitized 3D model data for the fabrication of custom trays, positioning guides for custom abutments, tooth preparation guides, provisional dental restorations, silicone indexes, occlusal devices, complete dentures, patterns to cast or press dental restorations, and surgical guides can be manufactured.

In the field of ceramics, Ebert et el [65] used zirconia suspension as a substrate for direct inkjet printing of a ceramic crown where the crown was printed as a dense green body which was subjected to debinding and subsequent sintering. According to this study, the mechanical properties of direct inkjet AM zirconia specimens were not significantly different compared to their milled equivalents. A 
similar study revealed that direct inkjet AM zirconia specimens had a higher flexural strength than their slip cast counterparts [66].

\section{MATERIAL EXTRUSION}

ME, also known as fused deposition modelling (FDM), uses thermoplastic polymers that are extruded from the heated nozzle of the printer to build the 3D object layer by layer onto a building platform that moves in the z-axis. Due to its low cost, ME is one of the most widely used 3D printing technologies. However, the surface finish and final quality of the AM product are inferior compared to other technologies [67]. One interesting modified version of $M E$ is robocasting which involves automatized extrusion of a pseudoplastic material from the nozzle [68].

\section{Dental applications using ME technologies}

Even though ME can be used to process polymers, the accuracy and surface roughness finish obtained is inferior compared to VP and MJ technologies. However, robocasting ME technology for the fabrication of ceramic dental crowns [5] may present potential use in the future. Yet, factors affecting robocasting of green ceramic objects such as critical nozzle height, $\mathrm{pH}$, and viscosity of the ceramic slurry have to be adjusted $[69,70]$. Wang et al [71] investigated these processing parameters and manipulated them for robocasting porcelain crowns. The surface finish of AM crowns fell within the clinically acceptable range of 20 and $50 \mu \mathrm{m}$. Likewise, Silva et el [72] utilized a similar technique for the fabrication of zirconia copings with similar results. 


\section{POWDER BASED FUSION}

Powder-based fusion (PBF) technologies utilize powdered substrates that are spread onto the building platform in layering fashion with the help of roller blades. Confirming to the prescribed crosssectional geometry, each layer is selectively fused prior to the sequential addition of the next one. Three types of PBF technologies are currently available: Selective Laser Melting (SLM), Selective Laser Sintering (SLS) and Electron Beam Melting (EBM) [73, 74]. Among these, SLS uses a highpowered laser beam (Na: YAG) that heats the powder in a sealed chamber to a temperature just below the melting point [75]. This results in partial melting and fusion of powder particles layer by layer [76]. SLM is similar to SLS, except for the fact that it heats the powder to its melting temperature, resulting in complete fusion of the powder particles. EBM uses a high energy electron beam in a noble gas environment like Argon. A tungsten filament (cathode) is then heated to a temperature of $3000^{\circ} \mathrm{C}$ to emit electrons where the anode causes an acceleration of the electron beam, directed towards the powdered metal with the help of magnetic coils. Collision of high energy electrons with the powdered metal transforms their kinetic energy to heat which is responsible for the fusion of metal powder. For thermal stability and reduction of internal stresses, a temperature of $700^{\circ} \mathrm{C}$ is maintained within the inert chamber $[77,78]$.

\section{Dental applications using PBF technologies}

PBF technologies can be harnessed for the fabrication of cobalt chromium (Co-Cr) and titanium (Ti) metal frameworks for removable partial dentures (RPDs), tooth- or implant-supported fixed dental prostheses. Furthermore, PBF has also been investigated in bench top studies for the fabrication of ceramic components in dentistry. 
Studies that have used PBF technologies for the fabrication of Co-Cr frameworks have investigated their accuracy and bond strength to ceramics. Accuracy of PBF as a manufacturing technique is extrapolated from gap measurements between the metal framework and the prepared abutment. In this regard, Huang et al [79] evaluated the marginal and internal fit of metal ceramic crowns fabricated using conventional lost wax technique and SLM where SLM Co-Cr metal ceramic crowns revealed better marginal fit than their conventionally fabricated analogues. The results were confirmed in a subsequent study [80]. As for the ceramic bond strength, no significant difference was reported between SLM and conventionally processed specimens $[81,82]$.

SLS has also been investigated for producing RPD frameworks. According to one study, SLS is a more precise technique that can produce RPDs with better mechanical properties than the conventional technique [83]. A clinical study has shown that the production of RPDs with laser sintering may lead to greater patient satisfaction [84] but a randomized study with a longer followup time is still needed to corroborate this proclamation. Other laboratory and clinical studies have evaluated metal structures of RPD processed by SLS and SLM [83-85] where mainly Co-Cr or Ti (Ti6Al4V) alloys were studied. One study focused on the adaptation of four types of RPD and their results showed that SLS achieved an acceptable fit for all types of prostheses. However, long span prostheses and large number of retainers processed by the conventional casting technique still demonstrated better accuracy than those printed by SLS [85].

SLM and EBM have also been investigated for the fabrication of $\mathrm{Co}-\mathrm{Cr}$ and $\mathrm{Ti}$ frameworks for implant-supported fixed dental prosthesis. Accuracy of such frameworks has been analysed by various reports in the literature. Akcin et al [86] investigated the fit of multi-unit Co-Cr frameworks fabricated using SLM, milling, and lost wax methods. The study revealed lowest marginal gap values for 3 and 4-unit SLM frameworks coupled with the highest values in the occlusal region of 5-unit 
SLM frameworks. Revilla-Leon et al [87] reported a clinically acceptable implant-abutment discrepancy for SLM manufactured complete-arch Co-Cr implant-supported frameworks measured using a coordinate measuring machine CMM. Similar results have been reported for SLM and EBM manufactured full arch implant supported Ti frameworks [74].

For processing dental ceramics, SLS has been tried [5], but owing to their high sintering temperature, direct SLA complicates the production of ceramic objects to their full density [88]. Indirect SLA is a practical approach for the manipulation of dental ceramics which involves the production of green ceramic object hybridized with polymeric binders [89].

\section{BINDER JETTING}

Binder Jetting (BJ) is a technology that was in fact inspired by ink jet printers. In this process, a powdered substrate is deposited onto a building platform in layers, which are subjected to selective deposition of binder droplets from the nozzle. In order to polymerize the binder, the printed structure is placed in a furnace. If the printed material is metal or ceramic, it needs to undergo an additional step of heat treatment or sintering, respectively [90].

\section{Dental applications using BJ technologies}

Limited number of studies are available with this technology one of which investigated the technology for the fabrication of green ceramic objects and manipulated the processing parameters for the fabrication of porcelain crowns [91]. 


\section{Limitations and future perspectives}

Based on the current literature, it could be stated that $A M$ has proven its potential on several fronts and withstood the test of time in dental industry. However, the conclusions extrapolated from these studies should be considered with caution, especially in regards to high standard deviations, low power, low number of operators involved in some studies. Since most of them are cross-sectional snapshots of bench-top investigations, the evidence substantiating the notion of AM integration into clinical practice remains inconclusive in particular for accuracy, trueness and gap measurements.

It could however be expected that AM combined with digital imaging technologies will have large implications in dentistry. The versatility of this technology makes it an ideal fit for the field of dentistry, which is known for its creativity and artistic aspects. However, cost of this technology and technical limitations for dental applications are thwarting its commercialization in the field dental medicine. Future research and development in the technology might help overcome the limitations of this technology, leading to widespread approbation and a possible diminution in the cost of its dental applications using metals, polymers and ceramics.

\section{Compliance with Ethical Standards}

\section{Conflict of Interest}

The authors declare that they have no conflict of interest.

\section{Human and Animal Rights and Informed Consent}

This article does not contain any studies with human or animal subjects performed by any of the authors. 


\section{References}

Papers of particular interest, published recently, have been highlighted as:

- Of importance

•. Of major importance

1. Brawek PK, Wolfart S, Endres L, Kirsten A, Reich S. The clinical accuracy of single crowns exclusively fabricated by digital workflow--the comparison of two systems. Clin Oral Investig. 2013;17:2119-25.

2. Van Noort R. The future of dental devices is digital. Dent Mater. 2012;28:3-12.

3. Duret F, Blouin J-L, Duret B. CAD-CAM in dentistry. J Am Dent Assoc. 1988;117:715-20.

4. Revilla-León M, Özcan M. Additive manufacturing technologies used for 3d metal printing in dentistry. Curr Oral Health Rep. 2017;4:201-8. *Literature review of polymer printing and main dental applications.

5. Methani MM, Revilla-León M, Zandinejad A. The potential of additive manufacturing technologies and their processing parameters for the fabrication of all-ceramic crowns: A review. $\mathrm{J}$ Esthet Restor Dent. 2020;32:182-92. *Literature review of ceramic printing and main dental applications.

6. Murphy SV, Atala A. 3D bioprinting of tissues and organs. Nat Biotechnol. 2014;32:773.

7. Babu PJ, Alla RK, Alluri VR, Datla SR, Konakanchi A. Dental ceramics: Part I. An overview of composition, structure and properties. J Eng Mater Technol. 2015;3:13-8.

8. Dawood A, Marti Marti B, Sauret-Jackson V, Darwood A. 3D printing in dentistry. Br Dent J. 2015;219:521-9.

9. Tumbleston JR, Shirvanyants D, Ermoshkin N, Janusziewicz R, Johnson AR, Kelly D, et al. Continuous liquid interface production of 3D objects. Science. 2015;347:1349. 
10. Stansbury JW, Idacavage MJ. 3D printing with polymers: Challenges among expanding options and opportunities. Dent Mater. 2016;32:54-64.

11. Infuehr R, Pucher N, Heller $\mathrm{C}$, Lichtenegger $\mathrm{H}$, Liska R, Schmidt $\mathrm{V}$, et al. Functional polymers by two-photon 3D lithography. Appl Surf Sci. 2007;254:836-40.

12. Liska R, Cziferszky M, Inführ R, Turecek C, Fritscher C, Seidl B, et al. Photopolymers for rapid prototyping. J Coat Technol Res. 2007;4:505-10.

13. Rossini G, Parrini S, Castroflorio T, Deregibus A, Debernardi CL. Diagnostic accuracy and measurement sensitivity of digital models for orthodontic purposes: A systematic review. Am J Orthod Dentofacial Orthop. 2016;149(2):161-70. ${ }^{* *}$ An important systematic review for AM diagnostic casts.

14. Patzelt SBM, Bishti S, Stampf S, Att W. Accuracy of computer-aided design/computer-aided manufacturing-generated dental casts based on intraoral scanner data. J Am Dent Assoc. 2014;145:1133-40.

15. Hazeveld A, Huddleston Slater JJ, Ren Y. Accuracy and reproducibility of dental replica models reconstructed by different rapid prototyping techniques. Am J Orthod Dentofacial Orthop. 2014;145:108-15.

16. Revilla-León M, Gonzalez-Martín Ó, Pérez López J, Sánchez-Rubio JL, Özcan M. Position accuracy of implant analogs on $3 \mathrm{~d}$ printed polymer versus conventional dental stone casts measured using a coordinate measuring machine. J Prosthodont. 2018;27:560-7.

17. Piedra Cascon W, Revilla-Leon M. Digital workflow for the design and additively manufacture of a splinted framework and custom tray for the impression of multiple implants: A dental technique. J Prosthet Dent. 2018;120:805-11. 
18. Revilla-Leon M, Sanchez-Rubio JL, Oteo-Calatayud J, Özcan M. Impression technique for a complete-arch prosthesis with multiple implants using additive manufacturing technologies. J Prosthet Dent. 2017;117:714-20.

19. Li X, Xie B, Jin J, Chai $Y$, Chen Y. 3D printing temporary crown and bridge by temperature controlled mask image projection stereolithography. Procedia Manuf. 2018;26:1023-33.

20. Dikova T. Production of high-quality temporary crowns and bridges by stereolithography. Scr Sci Med Dent. 2019;5:2019.

21. Digholkar S, Madhav VNV, Palaskar J. Evaluation of the flexural strength and microhardness of provisional crown and bridge materials fabricated by different methods. J Indian Prosthodont Soc. 2016;16:328-34.

22. Kang S-Y, Park J-H, Kim J-H, Kim W-C. Accuracy of provisional crowns made using stereolithography apparatus and subtractive technique. J Adv Prosthodont. 2018;10(5):354-60.

23. Revilla-Leon M, Meyers MJ, Zandinejad A, Özcan M. A review on chemical composition, mechanical properties, and manufacturing workflow of additively manufactured current polymers for interim dental restorations. J Adv Prosthodont: 2019;31(1):51-7. *Literature review of interim dental polymer printing.

24. Revilla-Leon M, Umorin M, Özcan M, Piedra-Cascon W. Color dimensions of additive manufactured interim restorative dental material. J Prosthet Dent. 2020 (in press)

25. Tahayeri A, Morgan M, Fugolin AP, Bompolaki D, Athirasala A, Pfeifer CS, et al. 3D printed versus conventionally cured provisional crown and bridge dental materials. Dent Mater. 2018;34:192-200.

26. Ahn J-J, Huh J-B, Choi J-W. In vitro evaluation of the wear resistance of provisional resin materials fabricated by different methods. J Korean Acad Prosthodont. 2019;57:110-7. 
27. Cho W-T, Choi J-W. Comparison analysis of fracture load and flexural strength of provisional restorative resins fabricated by different methods. J Korean Acad Prosthodont. 2019;57:225-31.

28. Alharbi N, Osman R, Wismeijer D. Effects of build direction on the mechanical properties of 3D-printed complete coverage interim dental restorations. J Prosthet Dent. 2016;115:760-7. ${ }^{* *}$ Mechanical properties of polymers related with print orientation.

29. Revilla-Leon M, Raney L, Piedra-Cascon W, Barrington J, Zandinejad A, Özcan M. Digital workflow for an esthetic rehabilitation using a facial and intraoral scanner and an additive manufactured silicone index: A dental technique. J Prosthet Dent. 2020;123:564-70.

30. Revilla-Leon M, Besne-Torre A, Sanchez-Rubio JL, Fabrega JJ, Özcan M. Digital tools and 3D printing technologies integrated into the workflow of restorative treatment: A clinical report. $\mathrm{J}$ Prosthet Dent. 2019;121:3-8.

31. Park SH, Piedra-Cascón W, Zandinejad A, Revilla-León M. Digitally created 3-piece additive manufactured index for direct esthetic treatment. J Prosthodont. 2020. (in press).

32. Revilla-León M, Fountain J, Cascón W, Özcan M, Zandinejad A. Workflow description of additively manufactured clear silicone indexes for injected provisional restorations: A novel technique. J Esthet Restor Dent. 2019;31.

33. Vasques MT, Mori M, Lagana DC. Three-dimensional printing of occlusal devices for temporomandibular disorders by using a free CAD software program: A technical report. J Prosthet Dent. 2020;123:232-5.

34. Vayrynen VO, Tanner J, Vallittu PK. The anisotropicity of the flexural properties of an occlusal device material processed by stereolithography. J Prosthet Dent. 2016;116:811-7. 
35. Huettig F, Kustermann A, Kuscu E, Geis-Gerstorfer J, Spintzyk S. Polishability and wear resistance of splint material for oral appliances produced with conventional, subtractive, and additive manufacturing. J Mech Behav Biomed Mater. 2017;75:175-9.

36. Berntsen C, Kleven M, Heian M, Hjortsjo C. Clinical comparison of conventional and additive manufactured stabilization splints. Acta Biomater Odontol Scand. 2018;4:81-9.

37. Waldecker M, Leckel M, Rammelsberg P, Bömicke W. Fully digital fabrication of an occlusal device using an intraoral scanner and 3D printing: A dental technique. J Prosthet Dent. 2019;121:576-80.

38. Lutz A-M, Hampe R, Roos M, Lümkemann N, Eichberger M, Stawarczyk B. Fracture resistance and 2-body wear of 3-dimensional-printed occlusal devices. J Prosthet Dent. 2019;121:166-72.

39. Prpic V, Slacanin I, Schauperl Z, Catic A, Dulcic N, Cimic S. A study of the flexural strength and surface hardness of different materials and technologies for occlusal device fabrication. $J$ Prosthet Dent. 2019;121:955-9.

40. Kawahata N, Ono H, Nishi Y, Hamano T, Nagaoka E. Trial of duplication procedure for complete dentures by CAD/CAM. J Oral Rehabil. 1997;24:540-8.

41. Goodacre CJ, Garbacea A, Naylor WP, Daher T, Marchack CB, Lowry J. CAD/CAM fabricated complete dentures: concepts and clinical methods of obtaining required morphological data. $\mathrm{J}$ Prosthet Dent. 2012;107:34-46.

42. Inokoshi M, Kanazawa M, Minakuchi S. Evaluation of a complete denture trial method applying rapid prototyping. Dent Mater J. 2012;31:40-6.

43. Bilgin MS, Erdem A, Aglarci OS, Dilber E. Fabricating Complete Dentures with CAD/CAM and RP Technologies. J Prosthodont. 2015;24:576-9. 
44. Maeda Y, Minoura M, Tsutsumi S, Okada M, Nokubi T. A CAD/CAM system for removable denture. Part I: Fabrication of complete dentures. Int J Prosthodont. 1994;7:17-21.

45. Chung YJ, Park JM, Kim TH, Ahn JS, Cha HS, Lee JH. 3D Printing of Resin Material for Denture Artificial Teeth: Chipping and Indirect Tensile Fracture Resistance. Materials. 2018;11.

46. Lee S, Hong SJ, Paek J, Pae A, Kwon KR, Noh K. Comparing accuracy of denture bases fabricated by injection molding, CAD/CAM milling, and rapid prototyping method. J Adv Prosthodont. 2019;11:55-64.

47. Kalberer N, Mehl A, Schimmel M, Muller F, Srinivasan M. CAD-CAM milled versus rapidly prototyped (3D-printed) complete dentures: An in vitro evaluation of trueness. J Prosthet Dent. 2019;121:637-43.

48. Fathi HM, Al-Masoody AH, El-Ghezawi N, Johnson A. The Accuracy of fit of crowns made from wax patterns produced conventionally (hand formed) and via CAD/CAM technology. Eur $\mathrm{J}$ Prosthodont Restor Dent. 2016;24:10-7.

49. Revilla-Leon M, Olea-Vielba M, Esteso-Saiz A, Martinez-Klemm I, Özcan M. Marginal and internal gap of handmade, milled and 3D printed additive manufactured patterns for pressed lithium disilicate onlay restorations. Eur J Prosthodont Restor Dent. 2018;26:31-8.

50. Williams RJ, Bibb R, Rafik T. A technique for fabricating patterns for removable partial denture frameworks using digitized casts and electronic surveying. J Prosthet Dent. 2004;91(1):85-8.

51. Mai HN, Lee KB, Lee DH. Fit of interim crowns fabricated using photopolymer-jetting 3D printing. J Prosthet Dent. 2017;118:208-15.

52. Kim D-Y, Jeon J-H, Kim J-H, Kim H-Y, Kim W-C. Reproducibility of different arrangement of resin copings by dental microstereolithography: Evaluating the marginal discrepancy of resin copings. J Prosthet Dent. 2017;117:260-5. 
53. Giacomo GAPD, Cury PR, de Araujo NS, Sendyk WR, Sendyk CL. Clinical application of stereolithographic surgical guides for implant placement: preliminary results. J Periodontol. 2005;76:503-7.

54. Reyes A, Turkyilmaz I, Prihoda TJ. Accuracy of surgical guides made from conventional and a combination of digital scanning and rapid prototyping techniques. J Prosthet Dent. 2015;113:295303.

55. Sarment DP, Sukovic P, Clinthorne N. Accuracy of implant placement with a stereolithographic surgical guide. Int J Oral Maxillofac Implants. 2003;18:571-7.

56. Ozan O, Turkyilmaz I, Ersoy AE, McGlumphy EA, Rosenstiel SF. Clinical accuracy of 3 different types of computed tomography-derived stereolithographic surgical guides in implant placement. $\mathrm{J}$ Oral Maxillofac Surg. 2009;67:394-401.

57. Revilla-León $M$, Sadeghpour $M$, Özcan $M$. An update on applications of 3D printing technologies used for processing polymers used in implant dentistry. Odontology. 2020 (in press) 58. Dehurtevent M, Robberecht L, Hornez JC, Thuault A, Deveaux E, Behin P. Stereolithography: A new method for processing dental ceramics by additive computer-aided manufacturing. Dent Mater. 2017;33:477-85. ${ }^{* *}$ An important review on additive manufacturing of dental ceramics. 59. Uçar $\mathrm{Y}$, Aysan Meriç I, Ekren O. Layered manufacturing of dental ceramics: Fracture mechanics, microstructure, and elemental composition of lithography-sintered ceramic. J Prosthodont. 2019;28:e310-e8.

60. Zandinejad A, Methani MM, Schneiderman ED, Revilla-León M, Bds DM. Fracture resistance of additively manufactured zirconia crowns when cemented to implant supported zirconia abutments: An in vitro study. J Prosthodont. 2019;28:893-7. 
61. Osman RB, van der Veen AJ, Huiberts D, Wismeijer D, Alharbi N. 3D-printing zirconia implants; a dream or a reality? An in-vitro study evaluating the dimensional accuracy, surface topography and mechanical properties of printed zirconia implant and discs. J Mech Behav Biomed Mater. 2017;75:521-8.

62. Gardan J. Additive manufacturing technologies: state of the art and trends. Int J Prod Res. 2016;54:3118-32.

63. Fahad M, Dickens P, Gilbert M. Novel polymeric support materials for jetting based additive manufacturing processes. Rapid Prototyp J. 2013;19:230-9.

64. Singh V. Rapid prototyping, materials for RP and applications of RP. Int J Sci Eng Res. 2013;4:473-80.

65. Ebert J, Özkol E, Zeichner A, Uibel K, Weiss Ö, Koops U, et al. Direct Inkjet Printing of Dental Prostheses Made of Zirconia. J Dent Res. 2009;88:673-6.

66. Özkol E, Zhang W, Ebert J, Telle R. Potentials of the "Direct inkjet printing" method for manufacturing 3Y-TZP based dental restorations. J Eur Ceram Soc. 2012;32:2193-201.

67. Liu Q, Leu MC, Schmitt SM. Rapid prototyping in dentistry: technology and application. Int J Adv Manuf Technol. 2006;29:317-35.

68. Feilden E, Blanca EG-T, Giuliani F, Saiz E, Vandeperre L. Robocasting of structural ceramic parts with hydrogel inks. J Eur Ceram Soc. 2016;36:2525-33.

69. Wang J, Shaw LL. Rheological and extrusion behavior of dental porcelain slurries for rapid prototyping applications. Mater Sci Eng A Struct Mater. 2005;397:314-21.

70. Vallar S, Houivet D, El Fallah J, Kervadec D, Haussonne JM. Oxide slurries stability and powders dispersion: optimization with zeta potential and rheological measurements. J Eur Ceram Soc. 1999;19:1017-21. 
71. Wang J, Shaw LL, Cameron TB. Solid freeform fabrication of permanent dental restorations via slurry micro-extrusion. J Am Ceram Soc. 2006;89:346-9.

72. Silva NR, Witek L, Coelho PG, Thompson VP, Rekow ED, Smay J. Additive CAD/CAM process for dental prostheses. J Prosthodont. 2011;20:93-6.

73. Revilla-Leon M, Meyer MJ, Özcan M. Metal additive manufacturing technologies: literature review of current status and prosthodontic applications. Int J Comput Dent. 2019;22(1):55-67. ${ }^{*}$ Comprehensive literature review on metal printing and main dental applications.

74. Revilla-Leon M, Ceballos L, Martinez-Klemm I, Özcan M. Discrepancy of complete-arch titanium frameworks manufactured using selective laser melting and electron beam melting additive manufacturing technologies. J Prosthet Dent. 2018;120:942-7.

75. Mazzoli A. Selective laser sintering in biomedical engineering. Med Biol Eng Comput. 2013;51:245-56.

76. Fischer P, Karapatis N, Romano V, Glardon R, Weber HP. A model for the interaction of nearinfrared laser pulses with metal powders in selective laser sintering. Appl Phys A Mater Sci Process. 2002;74:467-74.

77. Murr LE, Gaytan SM, Ramirez DA, Martinez E, Hernandez J, Amato KN, et al. Metal fabrication by additive manufacturing using laser and electron beam melting technologies. J Mater Sci Technol. 2012;28:1-14.

78. Vandenbroucke B, Kruth JP. Selective laser melting of biocompatible metals for rapid manufacturing of medical parts. Rapid Prototyp J. 2007;13:196-203.

79. Huang Z, Zhang L, Zhu J, Zhang X. Clinical marginal and internal fit of metal ceramic crowns fabricated with a selective laser melting technology. J Prosthet Dent. 2015;113:623-7. 
80. Kim KB, Kim JH, Kim WC, Kim JH. Three-dimensional evaluation of gaps associated with fixed dental prostheses fabricated with new technologies. J Prosthet Dent. 2014;112:1432-6.

81. Xiang N, Xin X-Z, Chen J, Wei B. Metal-ceramic bond strength of Co-Cr alloy fabricated by selective laser melting. J Dent. 2012;40:453-7.

82. Akova T, Ucar Y, Tukay A, Balkaya MC, Brantley WA. Comparison of the bond strength of laser-sintered and cast base metal dental alloys to porcelain. Dent Mater. 2008;24:1400-4.

83. Alageel O, Abdallah MN, Alsheghri A, Song J, Caron E, Tamimi F. Removable partial denture alloys processed by laser-sintering technique. J Biomed Mater Res B Appl Biomater. 2018;106:1174-85.

84. Almufleh B, Emami E, Alageel O, de Melo F, Seng F, Caron E, et al. Patient satisfaction with laser-sintered removable partial dentures: A crossover pilot clinical trial. J Prosthet Dent. 2018;119:560-7 e1.

85. Chen H, Li H, Zhao Y, Zhang X, Wang Y, Lyu P. Adaptation of removable partial denture frameworks fabricated by selective laser melting. J Prosthet Dent. 2020 (in press)

86. Akçin $\mathrm{ET}$, Güncü MB, Aktaş G, Aslan Y. Effect of manufacturing techniques on the marginal and internal fit of cobalt-chromium implant-supported multiunit frameworks. J Prosthet Dent. 2018;120:715-20.

87. Revilla-Leon M, Ceballos L, Özcan M. Implant prosthodontic discrepancy of complete-arch Co$\mathrm{Cr}$ implant frameworks manufactured through selective laser melting additive manufacturing technology using a coordinate measuring machine. Int J Oral Maxillofac Implants. 2019;34:698-707. 88. Shahzad K, Deckers J, Boury S, Neirinck B, Kruth J-P, Vleugels J. Preparation and indirect selective laser sintering of alumina/PA microspheres. Ceram Int. 2012;38:1241-7. 
89. Liu J, Zhang B, Yan C, Shi Y. The effect of processing parameters on characteristics of selective laser sintering dental glass-ceramic powder. Rapid Prototyp J. 2010;16:138-45.

90. Gaytan SM, Cadena MA, Karim H, Delfin D, Lin Y, Espalin D, et al. Fabrication of barium titanate by binder jetting additive manufacturing technology. Ceram Int. 2015;41(5, Part A):6610-9. 91. Miyanaji H, Yang L, Zhang S, Zandinejad A. A preliminary study of the graded dental porcelain ceramic structures fabricated via binder jetting 3D printing. Procedia Manuf. 2016;5:870-887. 